\title{
Interrelation between binocular disparity and other feature maps of V1 using Kohonen's SOFM algorithm
}

\author{
M Sultan M Siddiqui ${ }^{*}$, Mohit Kumar Garg², Basabi Bhaumik ${ }^{1}$ \\ From Nineteenth Annual Computational Neuroscience Meeting: CNS*2010 \\ San Antonio, TX, USA. 24-30 July 2010
}

Visual cortex possesses features such as binocular disparity (DP), ocular dominance (OD), orientation preference (OR), direction preference (DS), and spatial frequency. Neurophysiological studies have explored the existence of orthogonal relationship between local maps of DP and OD at visual cortex sites having vertical/near vertical OR [1]. No experimental studies relate DP map with: (i) OD map at sites other than vertical/near vertical OR, (ii) pinwheel singularities of OR map, and (iii) DS map. We have studied relationship of DP with other features maps such as OR, OD and DS, by jointly developing DP, OR, OD and DS feature maps using Kohonen's self-organising feature map (SOFM) algorithm. Existing models using Kohenen's algorithm implements feature maps of visual cortex as: (i) combined OR and OD [2], and (ii) combined OR and DS [3]. No model maps till date have attempted to model DP jointly with OR, OD and DS feature maps of visual cortex.

We use VMratio to measure interaction between DP and OD maps. VMratio is peak to baseline value of fitted von Mises function to histogram distribution of gradient direction differences between DP and OD maps.
VMratio $>3$ indicates high interaction and VM-ratio $<2$ indicates no interaction [1]. The gradient direction difference at which von Mises function peaks, defines the angle of crossing between DP and OD contours.

Indeed in our simulated maps, DP contour crosses OD contour orthogonally having a range from $45^{\circ}$ to $135^{\circ}$ with median near $90^{\circ}$ (VMratio > 3), for vertical/near vertical OR portions/sites. DP contour crosses OD contour having a range from $0^{\circ}$ to $45^{\circ}$ with median near $22.5^{\circ}$ (VMratio > 3 ), for horizontal/near horizontal OR portions/sites. DP map shows no relationship with: (i) pinwheel singularities of OR map (see Table 1) and (ii) DS map.

\section{Conclusions}

Our jointly modelled DP, OR, OD, and DS maps captures experimentally observed relationship among them [1,4-6]. We believe that ours is the first model that yields combined DP, OR, OD, and DS maps.

\section{Author details}

'Department of Electrical Engineering, Indian Institute of Technology Delhi, New Delhi, India. ${ }^{2}$ ADE DRDO Bangalore, Karnataka, India.

Table 1 Statistics of DP vs Pinwheel singularities

\begin{tabular}{|c|c|c|c|c|c|c|}
\hline \multirow[b]{2}{*}{ Pinwheel No.(DP mean) } & \multicolumn{6}{|c|}{ Range of DP } \\
\hline & $0^{\circ}-60^{\circ}$ & $60^{\circ}-120^{\circ}$ & $120^{\circ}-180^{\circ}$ & $180^{\circ}-240^{\circ}$ & $240^{\circ}-300^{\circ}$ & $300^{\circ}-360^{\circ}$ \\
\hline +ve Pinwheel No. (DP mean) & $\begin{array}{c}4 \\
\left(34.7^{\circ}\right)\end{array}$ & $\begin{array}{c}12 \\
\left(93.9^{\circ}\right)\end{array}$ & $\begin{array}{c}20 \\
\left(144.7^{\circ}\right)\end{array}$ & $\begin{array}{c}18 \\
\left(215.3^{\circ}\right)\end{array}$ & $\begin{array}{c}9 \\
\left(260.7^{\circ}\right)\end{array}$ & $\begin{array}{c}4 \\
\left(318.6^{\circ}\right)\end{array}$ \\
\hline -ve Pinwheel No. (DP mean) & $\begin{array}{c}4 \\
\left(34.3^{\circ}\right)\end{array}$ & $\begin{array}{c}14 \\
\left(93.3^{\circ}\right)\end{array}$ & $\begin{array}{c}18 \\
\left(153^{\circ}\right)\end{array}$ & $\begin{array}{c}16 \\
\left(208.6^{\circ}\right)\end{array}$ & $\begin{array}{c}11 \\
\left(275.3^{\circ}\right)\end{array}$ & $\begin{array}{c}4 \\
\left(311^{\circ}\right)\end{array}$ \\
\hline
\end{tabular}

* Correspondence: een068257@ee.iitd.ac.in

${ }^{1}$ Department of Electrical Engineering, Indian Institute of Technology Delhi, New Delhi, India 


\section{References}

1. Kara P, Boyd JD: A micro-architecture for binocular disparity and ocular dominance in visual cortex. Nature 2009, 458:627-632.

2. Obermayer K, Blasdel GG, Schulten K: Neural network model for the formation and for the spatial structure of retinotopic maps, orientation and ocular-dominance columns. Artif. neural nw. 1991, 505-511.

3. Swindale NV, Bauer $\mathrm{H}$ : Application of Kohonen's self-organising feature map algorithm to cortical maps of orientation and direction preference. Proc. Royal Soc. London 1998, 827-838.

4. Bartfeld E, Grinvald A: Relationship between orientation-preference pinwheels, cytochrome oxidase blobs, and ocular-dominance columns in primate striate cortex. Proc. Natl. Acad. Sci 1992, 89:11905-11909.

5. Crair MC, Ruthazer ES, Stryker MP: Ocular dominance peaks at pinwheel singularities of the orientation map in cat visual cortex. American physiology society 1997, 3381-3385.

6. Shmuel A, Grinvald A: Functional organization for direction of motion and its relationship to orientation maps in cat area 18. J. Neurosci 1996, 6945-6964.

doi:10.1186/1471-2202-11-S1-P81

Cite this article as: Siddiqui et al:: Interrelation between binocular disparity and other feature maps of V1 using Kohonen's SOFM algorithm. BMC Neuroscience 2010 11(Suppl 1):P81.

\section{Submit your next manuscript to BioMed Central} and take full advantage of:

- Convenient online submission

- Thorough peer review

- No space constraints or color figure charges

- Immediate publication on acceptance

- Inclusion in PubMed, CAS, Scopus and Google Scholar

- Research which is freely available for redistribution

Submit your manuscript at www.biomedcentral.com/submit 